\title{
Gene expression profiling of porcine mammary epithelial cells after challenge with Escherichia coli and Staphylococcus aureus in vitro
}

Alexandra Jaeger ${ }^{1}$, Danilo Bardehle², Michael Oster ${ }^{1}$, Juliane Günther ${ }^{1}$, Eduard Muráni', Siriluck Ponsuksili' Klaus Wimmers ${ }^{1 *}$ and Nicole Kemper ${ }^{3}$

\begin{abstract}
Postpartum Dysgalactia Syndrome (PDS) represents a considerable health problem of postpartum sows, primarily indicated by mastitis and lactation failure. The poorly understood etiology of this multifactorial disease necessitates the use of the porcine mammary epithelial cell (PMEC) model to identify how and to what extent molecular pathogen defense mechanisms prevent bacterial infections at the first cellular barrier of the gland. PMEC were isolated from three lactating sows and challenged with heat-inactivated potential mastitis-causing pathogens Escherichia coli (E. coli) and Staphylococcus aureus (S. aureus) for $3 \mathrm{~h}$ and $24 \mathrm{~h}$, in vitro. We focused on differential gene expression patterns of PMEC after pathogen challenge in comparison with the untreated control by performing microarray analysis. Our results show that a core innate immune response of PMEC is partly shared by E. coli and S. aureus. But E. coli infection induces much faster and stronger inflammatory response than $S$. aureus infection. An immediate and strong up-regulation of genes encoding cytokines (IL1A and IL8), chemokines (CCL2, CXCL1, CXCL2, CXCL3, and CXCL6) and cell adhesion molecules (VCAM1, ICAM1, and ITGB3) was explicitly obvious post-challenge with $E$. coli inducing a rapid recruitment and activation of cells of host defense mediated by ILIB and TNF signaling. In contrast, $S$. aureus infection rather induces the expression of genes encoding monooxygenases (CYP1A1, CYP3A4, and CYP1B1) initiating processes of detoxification and pathogen elimination. The results indicate that the course of PDS depends on the host recognition of different structural and pathogenic profiles first, which critically determines the extent and effectiveness of cellular immune defense after infection.
\end{abstract}

\section{Introduction}

Postpartum Dysgalactia Syndrome (PDS), with Coliform Mastitis (CM) as cardinal symptom, is known as a multifactorial infectious disease in postpartum sows and a serious problem with high economic relevance in modern piglet production worldwide [1]. Significant milk production failure and other clinical signs including increased rectal temperature $\left(>39.3^{\circ} \mathrm{C}\right)$ postpartum, loss of appetite or low water intake, redness and inflammation of teats, pain, failure to expose teats and nurse, and sometimes vaginal discharge are typical indicators of affected animals [2]. While initial research focused on husbandry- and management-influenced occurrence of

\footnotetext{
* Correspondence: wimmers@fbn-dummerstorf.de

'Institute for Genome Biology, Leibniz-Institute for Farm Animal Biology, Wilhelm-Stahl-Allee 2, D-18196 Dummerstorf, Germany

Full list of author information is available at the end of the article
}

PDS, current studies rather concentrate on the role of causative pathogens, immune defense mechanisms, infection pressure and genetic predisposition. Gramnegative pathogens, e.g. Escherichia coli (E. coli) and gram-positive pathogens, e.g. Staphylococcus aureus (S. aureus) were most commonly isolated from milk of PDS-positive, but also from non-affected sows $[3,4]$. The major question is why only some sows develop subclinical or clinical signs of infection within $12 \mathrm{~h}$ to $48 \mathrm{~h}$ postpartum after contact with ubiquitous bacteria while others remain clinically healthy. Frequency and severity of this complex disease appear to depend on immune competence including resistance to infection of the sow. While the heritability of CM resistance has been estimated in a range from 0.02 up to 0.20 [5], further genetic studies on mastitis susceptibility are lacking. Extremely low infectious dose for colonization of 
mammary gland of sows of less than 100 coliform microorganisms [6] abet microbial mammary tissue invasion. In sows as well as in other animal species $E$. coli pathogenesis has been associated with lipopolysaccharide (LPS) endotoxin release inducing acute and severe inflammation [7]. In contrast, mastitis induced by S. aureus infection is mostly characterized as subclinical, mild and persistent [8]. Pathogenesis of both infections may proceed to pathogen clearance or to chronic infection depending on the effectiveness of host defense mechanisms especially at early stages of cellular response [8]. When pathogens have overcome physical barriers and entered the lumen of the mammary gland through the teat canal, macrophages and mammary epithelial cells (MEC) are important for initiating and driving the immediate non-specific innate immune response [9]. Inflammation response of periparturient sows after inoculation of porcine mammary gland with different potential mastitis-causing E. coli strains specified a dominant role of that pathogen species in CM [10]. The development of clinical symptoms of $\mathrm{CM}$ in the sow was suggested to be associated with a locally increased production of pro-inflammatory cytokines such as interleukin 1-beta (IL1-beta), IL6, IL8, and tumor necrosis factor-alpha (TNF-alpha) in response to intramammary E. coli infection $[10,11]$. Additionally, the time of infection of the mammary gland relative to parturition and the number of circulating neutrophils at the time of infection were shown to influence the development of clinical CM in the sow [12]. No published study was found regarding the inflammatory response of periparturient sows after inoculation of mammary gland with $S$. aureus. But it was commonly shown that E. coli and $S$. aureus are also the main causative agents of bovine mastitis, the most economically important disease of dairy ruminants. Comparative kinetic studies on infected udder of cows and inoculation of primary bovine mammary epithelial cells (pbMEC) with $E$. coli and $S$. aureus showed that $E$. coli swiftly and strongly induced the expression of cytokines and bactericidal factors, while $S$. aureus elicited a retarded response and failed to quickly induce the expression of bactericidal factors [8]. Both pathogens induced similar patterns of immune response genes, but the host response to $E$. coli was observed to be much faster and stronger than that to S. aureus infection [8]. Also different expression profiles of upstream as well as downstream regulators of early responses of pbMEC to E. coli and S. aureus may contribute to the different clinical manifestations and outcome of mastitis caused by these two pathogens [13]. Except for few referred studies on pathogen defense mechanisms of porcine mammary glands, the role of porcine mammary epithelial cells (PMEC) in the initiation of the innate immune response remains largely unknown. Our study focused on inflammatory response mechanisms of PMEC, isolated from lactating sows, after challenge with potential mastitis-causing pathogens such as $E$. coli and $S$. aureus. Strains from both pathogens used in our study were isolated from milk of PDSpositive sows. The molecular characterization of affected signaling pathways and involved signaling molecules in PMEC dependent on challenge time was performed by microarray analysis. Similarities and differences in the response of PMEC to both heat-inactivated pathogen species were determined by comparing the expression profile between the pathogen-challenged PMEC groups and unchallenged control as well as among the challenged groups. Selective analysis of most and strongest affected molecular and cellular functions, canonical pathways, upstream regulators and signaling networks were performed to throw light on the role of PMEC in pathogen clearance after bacterial invasion. Our results may especially improve the understanding of the specific reaction of PMEC to pathogen challenge and may help to get insight in how and to what extent environmental bacteria trigger inflammatory and immune responses in porcine mammary gland in general. To our knowledge, this is the first microarray-based study investigating genetic factors that determine the initial immune response of PMEC in vitro, at $3 \mathrm{~h}$ and at $24 \mathrm{~h}$ post-challenge (hpc) with heat-inactivated E. coli and S. aureus strains, potentially causing mastitis of sows.

\section{Materials and methods}

\section{Cell culture and pathogen challenge}

Primary cell cultures were established from mammary glands of three lactating sows of commercial herds. Animal care and tissue collection was performed in compliance with the German Law of Animal Protection. The experimental protocol was approved by the Animal Care Committee of the Leibniz-Institute for Farm Animal Biology, Dummerstorf, Germany. Tissues from eight mammary complexes cranial of the navel were collected aseptically immediately after slaughter from each individual. Subsequently, tissue samples were washed in Hank's Balanced Salt Solution (HBSS, PAN Biotech, Aidenbach, Germany) containing $17 \mathrm{mM}$ 4-(2-hydroxyethyl)-1piperazineethanesulfonic acid (HEPES, PAN Biotech) and 2\% Antibiotic/Antimycotic Solution (APS, $10000 \mathrm{U} / \mathrm{mL}$ penicillin, $10 \mathrm{mg} / \mathrm{mL}$ streptomycin sulphate, $25 \mu \mathrm{g} / \mathrm{mL}$ amphotericin B, PAA, Cölbe, Germany). After a second washing step, tissue samples were finely minced using sharp blades and placed in $15 \mathrm{~mL}$ falcon tubes. Washing steps were repeated until the supernatant was clear. Tissue digestion steps were performed in collagenase solution (Type III, $200 \mathrm{U} / \mathrm{mL}$, Biochrom, Berlin, Germany) at $37{ }^{\circ} \mathrm{C}$ for $45 \mathrm{~min}$. Occasionally, digested tissue was mixed with washing buffer and filtered through stainless 
steel meshes (100-380 $\mu \mathrm{m}$ pore size, Sigma-Aldrich, Steinheim, Germany) to remove undissociated tissue and debris. Cells were collected by centrifugation at $1000 \mathrm{rpm}$ and $15{ }^{\circ} \mathrm{C}$ for $10 \mathrm{~min}$ and pellets were resuspended in washing buffer without APS. This step was repeated until the supernatant was clear (3-4 digestion steps in total). At the end, cell pellets were resuspended in complete medium consisting of Dulbecco's Modified Eagle Medium/Nutrient Mixture F-12 (DMEM/F12, PAN Biotech), 10\% fetal bovine serum (FBS, PAA), 1\% APS, $10 \mu \mathrm{g} / \mathrm{mL}$ insulin (Sigma-Aldrich) and $1 \mu \mathrm{g} / \mathrm{mL}$ hydrocortisone (Sigma-Aldrich). Primary cells were cryopreserved in 90\% FBS and 10\% dimethyl sulfoxide (DMSO, Carl Roth, Karlsruhe, Germany). Before starting the experiments, cells were thawn, plated onto collagencoated (1:10 collagen $\mathrm{R}$ in destilled water, Menal, Emmendingen, Germany) $10 \mathrm{~cm}$ petri dishes and cultured in complete medium for several days at $37^{\circ} \mathrm{C}$ and $5 \% \mathrm{CO}_{2}$ in a humidified atmosphere. Fibroblasts, adipocytes and other cell types were removed by selective trypsinization (Trypsin/EDTA $(0.25 \% / 0.02 \%$, Sigma-Aldrich) during the following days. These cell types detach more rapidly from plastic after trypsinization than do the epithelial cell islands. The culture was quickly rinsed with growth medium to stop the enzymatic dispersion and to remove the fibroblastic cell areas. The relatively undisturbed epithelial cell islands were further incubated with growth medium. This procedure was repeated several times until a uniform and confluent monolayer of epithelial cells was formed.

Staphylococcus aureus (not characterized) and E. coli (gMEc240, sequence type 101, phylogroup B1, C+) strains used for this experiment were isolates from milk of PDS-positive sows. Both strains were grown in brainheart-infusion-broth (BHB, Oxoid, Wesel, Germany) at $37{ }^{\circ} \mathrm{C}$ to the logarithmic phase of culture growth (Optical Density at $600 \mathrm{~nm}\left[\mathrm{OD}_{600}\right] 0.5, \sim 5 \times 10^{7} / \mathrm{mL}$ ). Dilution series were plated to calibrate cell counts from the OD readings. Heat-inactivation of bacteria was performed at $80{ }^{\circ} \mathrm{C}$ for $1 \mathrm{~h}$ and verified by control plating. Afterwards, bacteria were spun down at $3000 \mathrm{rpm}$ for 15 min, washed twice with DMEM/F12 medium and resuspended herein at a density of $1 \times 10^{8} / \mathrm{mL}$. Aliquots were stored at $-20{ }^{\circ} \mathrm{C}$.

Approximately $4.4 \times 10^{5}$ of the isolated PMEC from each individual (three biological replicates) were seeded and cultured in collagen-coated 6-well plates in complete medium without APS (three technical replicates per individual and treatment condition). On the next day, medium was changed. Forty eight hours after seeding, cells reached $90 \%$ confluency. PMEC were challenged with $10^{7} / \mathrm{mL}$ heat-inactivated $S$. aureus and E. coli, respectively, for $3 \mathrm{~h}$ and for $24 \mathrm{~h}$ (Figure 1A). Equivalent challenge treatments have been considered as robust cell stimulation based on previously published reports. After incubation periods, pathogen-challenged and unchallenged cells (control) were washed three times with phosphate buffered saline (PBS, PAA) to remove the bacteria. Cells were collected for total RNA isolation.

\section{Immunocytochemistry/microscopy}

PMEC were seeded on $12 \mathrm{~mm}$ coverslips (Carl Roth) in 24-well plate (Biochrom) at a density of 10000 cells/well. After two days of culturing, medium was discarded, and coverslips were washed twice with PBS and fixed with ice-cold methanol $\left(-20{ }^{\circ} \mathrm{C}\right.$, Carl Roth) for $20 \mathrm{~min}$. Cells were permeabilized with $0.2 \%$ Triton X-100 (Carl Roth), diluted with PBS for $5 \mathrm{~min}$ and washed twice with PBS. Non-specific binding sites were blocked by incubating the coverslips with $10 \%$ FBS in PBS for $30 \mathrm{~min}$ at room temperature. Coverslips were washed twice with PBS and incubated with mouse anti-cytokeratin 18-fluorescein isothiocyanate (anti-Cy18-FITC, Sigma-Aldrich) and mouse anti-alphasmooth muscle actin antibodies (clone 1A4, SigmaAldrich), respectively in a humidified chamber for $1 \mathrm{~h}$. Coverslips were washed three times with PBS. Bound anti-alpha-smooth muscle actin antibody was visualized by $1 \mathrm{~h}$ incubation of the coverslips with goat antimouse FITC-labeled secondary antibody (Sigma-Aldrich). Nuclei of the cells were stained with 4,6-diamidino-2phenylindole (DAPI, Carl Roth) for 15 min. Coverslips were washed twice with PBS, air dried and mounted with 1,4-diazabicyclo[2.2.2] octane (DABCO) on glass slides (both from Carl Roth). Coverslips were analyzed by immunofluorescence microscopy (Microphot-FXA, Nikon, Düsseldorf, Germany).

\section{RNA extraction, target preparation, and hybridization}

Total RNA was isolated using the TRI ${ }^{\circ}$ reagent (SigmaAldrich) according to the manufacturer's instructions. Isolated RNA was purified using RNeasy Mini Kit (Qiagen, Hilden, Germany), and contaminating DNA was removed by DNase I digestion (Qiagen). RNA integrity and quantity were checked by agarose gel electrophoresis and by spectrometry with a NanoDrop ND1000 spectrophotometer (PEQLAB, Erlangen, Germany). Absence of DNA contamination was verified by PCR of the porcine beta-actin gene (forward primer, GAGAAG CTCTGCTACGTCGC, reverse primer, CCTGATGTC CACGTCGCACT, Promega, Mannheim, Germany) with isolated RNA as templates. For the microarray analysis individual biotin-labeled cRNA was synthesized by the Gene Chip 3' Express Kit (Affymetrix, Santa Clara, CA, USA). cRNA was fragmented ( $100 \mathrm{bp})$ and hybridized for $16 \mathrm{~h}$ at $45{ }^{\circ} \mathrm{C}$ to Affymetrix Gene Chip Porcine Genome Arrays. The microarrays were scanned using GeneChip Scanner 3000 (Affymetrix). Raw data was 


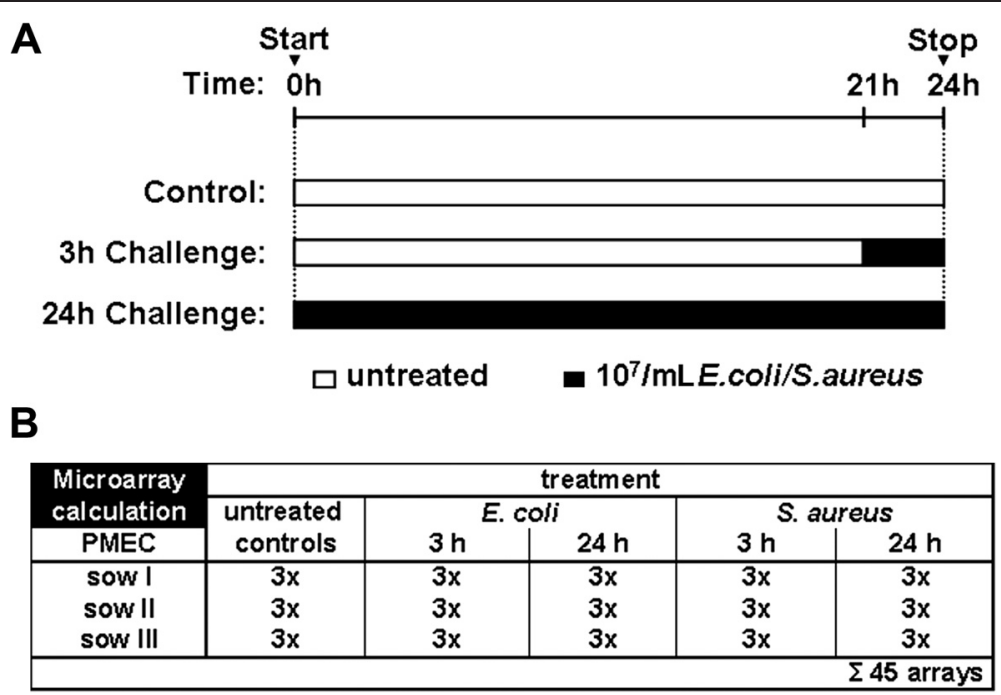

Figure 1 Schema of experimental setting. (A) Confluent PMEC cultures were challenged with $10^{7} / \mathrm{mL}$ heat-inactivated S. aureus and E. coli, respectively, for $3 \mathrm{~h}$ and $24 \mathrm{~h}$. In parallel unchallenged control cells were cultivated. After incubation periods, cells were collected and total RNA was isolated. (B) PMEC isolated from three lactating sows represent three biological replicates. Three technical replicates were analysed of each challenge (S. aureus, E. coli), unchallenged control and the two challenge times ( 3 h, 24 h), respectively. A total of 45 microarrays were obtained.

deposited in a MIAME-compliant database [14,15] (accession number: GSE64246).

\section{Microarray data analysis}

A microarray experiment was conducted in triplicate; three biological replicates were performed for each bacterial strain and experimental condition $(3 \mathrm{~h}, 24 \mathrm{~h}$, and control). A total of 45 microarrays were analysed (Figure 1B). Five experimental groups were built, including cells challenged with E. coli ( $3 \mathrm{hpc}$ and $24 \mathrm{hpc}$ ), cells challenged with $S$. aureus (3 hpc and $24 \mathrm{hpc}$ ) and unchallenged control cells. Data pre-processing was done using Bioconductor/ $\mathrm{R}$ packages. After quality control [16], background correction and data normalization were performed using GC-RMA ( $\log 2)$. To improve statistical power [17], inappropriate probe sets were excluded from further analysis due to three criteria: (i) probe sets absent in $>50 \%$ of PMEC culture within each experimental group (MAS5 filtering); (ii) probe sets with a small standard deviation $(\mathrm{SD}<0.2)$; (iii) probe sets with a small mean value $(M<2.5)$. A mixed-model analysis was performed using statistical analysis software (SAS, SAS Institute, Cary, NC, USA) to determine relative changes in mRNA levels, including effects mediated by experimental group and individual animal $\left[\mathrm{V}_{\mathrm{ij}}=\mu+\right.$ experimental group $\left._{\mathrm{i}}+\operatorname{animal}_{\mathrm{j}}+\mathrm{e}_{\mathrm{ij}}\right]$. Corresponding $\mathrm{q}$-values were calculated to estimate the proportion of false positives among all significant hypotheses and thus to correct for multiple testing [18]. Alterations in transcript abundances were considered to be statistically significant at $p<0.05$ and $\mathrm{q}<0.05$. Subsequently, data was filtered by fold change $(\mathrm{FC}<-1.5$; $\mathrm{FC}>1.5)$. The Ensembl gene annotation (Sus scrofa 9) was used as previously described [19]. A principal component analysis (PCA) was performed in $\mathrm{R}$ to assess an overall trend about the gene expression data and inspection about outliers. Gene lists from microarray results (Additional files 1, 2, 3 and 4) were evaluated with Ingenuity Pathway Analysis (IPA, Ingenuity Systems, Redwood City, CA, USA) to identify most affected molecular and cellular functions, canonical pathways, upstream regulators, and functional networks ( $p \leq 0.05$, Fisher's exact test).

\section{Real-time quantitative PCR}

First strand cDNA synthesis was performed with the same RNA samples used for the microarray analysis applying SuperScript III MMLV reverse transcriptase (Invitrogen, Karlsruhe, Germany) in a reaction containing $1 \mu \mathrm{g}$ RNA, $500 \mathrm{ng}$ oligo (dT)13VN primer and $500 \mathrm{ng}$ random hexamer primers (Promega) according to the manufacturer's protocol. Real-time quantitative PCR (RT-qPCR) was performed in duplicate to validate the differential expression results. Quantification of mRNA copy numbers was performed on a LightCycler 480 System using the LightCycler 480 SYBR Green I Master (all Roche Applied Science). Sequences of the oligonucleotide primers used (Sigma-Aldrich) and amplicons are given in Additional file 5. The reaction conditions for PCR were as follows: initial denaturation step at $95{ }^{\circ} \mathrm{C}$ for $5 \mathrm{~min}$ and 45 cycles consisting of denaturation at $95{ }^{\circ} \mathrm{C}$ for $10 \mathrm{~s}$, annealing at $60{ }^{\circ} \mathrm{C}$ for $15 \mathrm{~s}$ and extension/ fluorescence acquisition at $72{ }^{\circ} \mathrm{C}$ for 25 s. Melting curve 
analysis and agarose gel electrophoresis were performed after completion of the qPCR run to confirm specificity of the amplification and absence of primer dimers. Threshold cycles were converted to copy numbers using a standard curve generated by amplifying serial dilutions of an external PCR-generated standard $\left(10^{8}-10^{2}\right.$ copies). The calculated copy numbers were normalized with a factor derived from expression of the reference genes HPRT1 and RN7SK according to the method described by Vandesompele et al. [20]. Significance of differences was assessed with ANOVA. The results were declared to be statistically significant at $p<0.05$. Spearman's Rank Correlation was used to compare microarray and RTqPCR measurements using the SAS 9.3 software (SAS Institute, Inc., Cary, NC, USA).

\section{Results}

\section{Morphological characterization of PMEC cultures}

Heterogeneous population of epithelial, fibroblast-like, and adipose cells isolated from mammary glands of lactating sows were purified by continuous removal of non-epithelial cells by trypsin/EDTA treatment. Fibroblastic cells detached from their substratum, while epithelial cells were found to be more resistant. Most of the PMEC had a typical cobblestone shape and were connected tightly, visualized by phase contrast microscopy (Figure 2A). The purity of PMEC cultures was determined by immunocytochemistry. Cytokeratin elements of the PMEC cytoskeleton were stained with specific anti-cytokeratin-18 antibody. Almost all of the cells in our primary cell cultures were positive for cytokeratin18 staining ( 97\%) confirming high purity of luminal epithelial cells (Figure 2B). Some cells were found negative for cytokeratin-18 staining, but positive for alphasmooth muscle actin staining ( $3 \%)$ with a specific antibody showing that only few myoepithelial cells were present in our PMEC cultures (Figure 2C). The homogeneity of our established PMEC cultures ensures clarity and reproducibility of the subsequent experimental results.

\section{PMEC respond more prominently and earlier to challenge} with $\mathrm{E}$. coli than to challenge with $\mathrm{S}$. aureus

Gene expression profiling of PMEC from three lactating sows was performed at $3 \mathrm{hpc}$ and at $24 \mathrm{hpc}$ with E. coli and $S$. aureus, respectively, in comparison with unchallenged control cells using Affymetrix Gene Chip ${ }^{\circ}$ Porcine Genome Arrays. Filtering of raw data based on MAS5 algorithm and variability of expression of probe sets revealed 8494 probe sets for further analysis. A principal component analysis (PCA) showed that PMEC biological replicates were distantly clustered indicating individual differences, but had some similarity and reproducibility within the five experimental groups (Additional file 6). These were clustered into three distinct coloured groups (green dots: control; red dots: E. coli-challenge; blue dots: $S$. aureus-challenge) according to the density and consisting of three technical replicates, respectively. It was also shown that gene expression diverged most significantly with increasing challenge time ( $3 \mathrm{~h}$ to $24 \mathrm{~h}$ ). No outliers were detected. Further data analysis showed that more genes were differentially expressed at $24 \mathrm{~h}$ compared to $3 \mathrm{~h}$ after pathogen challenge, and following challenge with E. coli compared to challenge with S. aureus (Figures 3A-D). Significant expression changes of 156 and 1250 genes were observed at $3 \mathrm{hpc}$ and at $24 \mathrm{hpc}$ with $E$. coli, respectively. The expressions of 73 and 1073 genes were altered at $3 \mathrm{hpc}$ and at $24 \mathrm{hpc}$ with $\mathrm{S}$. aureus, respectively. Approximately $50 \%$ of the genes which were differentially expressed at $3 \mathrm{hpc}$ with $S$. aureus also differed at $3 \mathrm{hpc}$ with $E$. coli (Figure 3E). But $85 \%$ of the genes which were
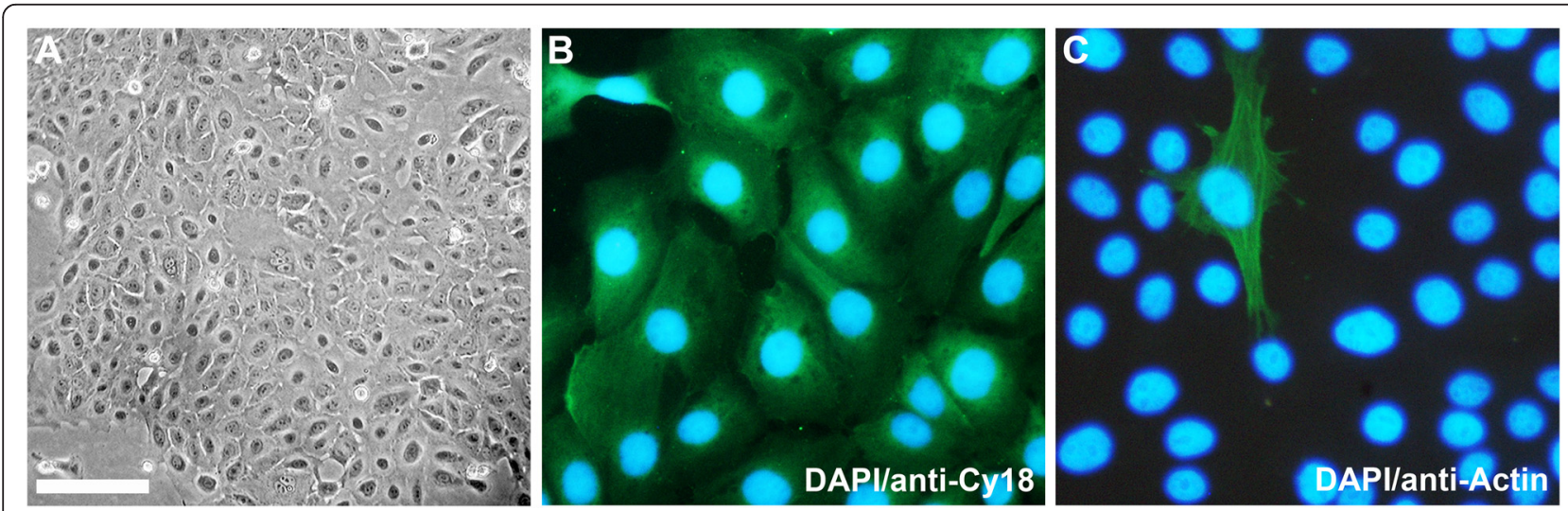

Figure 2 Validation of cell types in PMEC cultures. (A) Phase contrast micrograph of a confluent PMEC monolayer grown on collagen-coated tissue culture dishes demonstrating typical epithelial cobblestone morphology (bar = $100 \mu m$ ). (B) Dominant luminal mammary epithelial cells were stained with anti-cytokeratin-18 antibody (anti-Cy18, green fluorescence; nuclei, DAPI, blue fluorescence). (C) Sporadically found myoepithelial cells were stained with anti-smooth muscle actin antibody (anti-Actin, green fluorescence; nuclei, DAPI, blue fluorescence). 
A

\begin{tabular}{l|r|r}
\multicolumn{3}{c}{ Control vs. E. coli } \\
\multicolumn{1}{|c|}{$3 \mathrm{~h}$} & $24 \mathrm{~h}$ \\
\hline up & 114 & 519 \\
down & 42 & 731
\end{tabular}

C

Control

vs.

E. coli

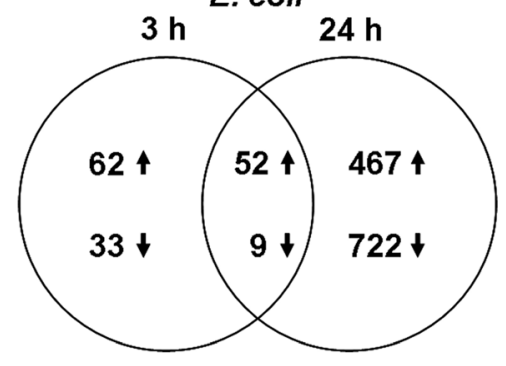

$\mathbf{E}$

Control

vs.

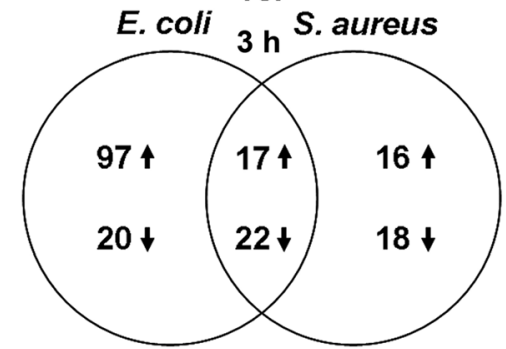

B

Control vs. S. aureus

\begin{tabular}{l|r|r} 
& $3 \mathrm{~h}$ & $24 \mathrm{~h}$ \\
\hline up & 33 & 399 \\
down & 40 & 674
\end{tabular}

D

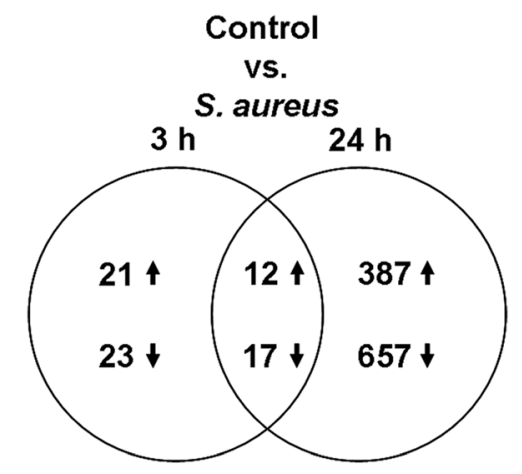

F

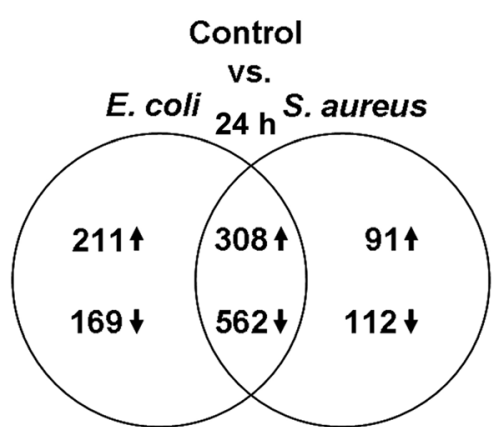

Figure 3 Significantly differentially expressed genes comparing E. coli-challenged and S. aureus-challenged PMEC. (A, B) More genes were differentially expressed at $24 \mathrm{~h}$ than at $3 \mathrm{~h}$ after pathogen challenge, and following challenge with $E$. coli than challenge with $\mathrm{S}$. aureus. (C-F) Venn diagrams showing numbers of differentially expressed genes as a function of time and pathogen stimulus vs. untreated PMEC (control) of three independent biological replicates; $p<0.05, q<0.05,-1.5>F C>1.5$. The numbers in the intersections represent the genes differentially expressed in the two groups. The early response of PMEC to both pathogen species (3 hpc, $\mathbf{E}$ ) was followed by a late, more intensive host response (24 hpc, F).

up-regulated at 3 hpc with $E$. coli were not found upregulated at $3 \mathrm{hpc}$ with $S$. aureus (Figure $3 \mathrm{E}$ ). The early response of PMEC to both pathogen species $(3 \mathrm{hpc})$ was followed by a late more intensive host response $(24 \mathrm{hpc})$ as indicated by an 8 -fold and 14-fold increase of differentially expressed genes at $24 \mathrm{hpc}$ with E. coli and S. aureus, respectively (Figures 3A-D). However, the number of shared up- and down-regulated genes was increased up to a maximum of $80 \%$ at $24 \mathrm{hpc}$ with both pathogen species (Figure 3F).

Molecular and cellular functions predominantly affected in PMEC by $E$. coli and S. aureus are different at $3 \mathrm{~h}$, but similar at $24 \mathrm{~h}$ post-challenge

Top five categories of molecular and cellular functions which were affected in PMEC at $3 \mathrm{hpc}$ and at $24 \mathrm{hpc}$ with $E$. coli or $S$. aureus were identified using Ingenuity Pathway Analysis (IPA) software (Table 1). At 3 hpc with
E. coli, most of the differentially expressed genes in PMEC were categorized by functions comprising "gene expression", "cellular movement", "cellular growth and proliferation", "cellular development", and "cell death and survival". Except for the two first named categories, all other molecular and cellular functions are also affected in cells at $24 \mathrm{hpc}$ with $E$. coli. Additionally, at the same time, differentially expressed genes associated with "RNA post-transcriptional modification" and "cell cycle" were affected by challenge with $E$. coli. In contrast, at 3 hpc of PMEC with $S$. aureus, most differentially expressed genes were categorized by functions comprising "small molecule biochemistry", "drug metabolism", "lipid metabolism", "vitamin and mineral metabolism", and "energy production". Genes belonging to these functional categories were also affected at $3 \mathrm{hpc}$ with $E$. coli, but were not predominantly involved in the early response of PMEC to this pathogen as well as 
Table 1 Molecular and cellular functions affected in PMEC by pathogen challenge

\begin{tabular}{|c|c|c|}
\hline $\begin{array}{l}3 \mathrm{~h} E \text {. coli-challenged vs. } \\
\text { unchallenged control cells }\end{array}$ & $p$-value & \#Molecules \\
\hline Gene Expression & $1.72 \mathrm{E}-14-1.71 \mathrm{E}-04$ & 46 \\
\hline Cellular Growth and Proliferation & $3.56 \mathrm{E}-14-3.13 \mathrm{E}-04$ & 55 \\
\hline Cellular Development & $1.46 \mathrm{E}-13-3.95 \mathrm{E}-04$ & 52 \\
\hline Cell Death and Survival & $1.29 \mathrm{E}-11-3.95 \mathrm{E}-04$ & 50 \\
\hline Cellular movement & 4.13E-11 - 3.95E-04 & 40 \\
\hline $\begin{array}{l}3 \mathrm{~h} \text { S. aureus-challenged vs. } \\
\text { unchallenged control cells }\end{array}$ & $p$-value & \#Molecules \\
\hline Small Molecule Biochemistry & 4.30E-08 - 4.53E-03 & 14 \\
\hline Drug Metabolism & $2.15 \mathrm{E}-07-4.53 \mathrm{E}-03$ & 8 \\
\hline Lipid Metabolism & $2.15 \mathrm{E}-07-4.53 \mathrm{E}-03$ & 11 \\
\hline Vitamin and Mineral Metabolism & $2.15 \mathrm{E}-07-3.39 \mathrm{E}-03$ & 4 \\
\hline Energy Production & 8.97E-07 - 2.27E-03 & 4 \\
\hline $\begin{array}{l}24 \mathrm{~h} \mathrm{E} \text {. coli-challenged vs. } \\
\text { unchallenged control cells }\end{array}$ & $p$-value & \#Molecules \\
\hline Cellular Growth and Proliferation & $1.46 \mathrm{E}-15-5.35 \mathrm{E}-03$ & 255 \\
\hline RNA Post-Transcriptional Modification & $3.21 \mathrm{E}-14-4.88 \mathrm{E}-03$ & 53 \\
\hline Cell Cycle & $1.46 \mathrm{E}-12-4.88 \mathrm{E}-03$ & 115 \\
\hline Cell Death and Survival & 7.44E-10 - 5.09E-03 & 226 \\
\hline Cellular Development & 4.90E-08 - 5.35E-03 & 219 \\
\hline $\begin{array}{l}24 \mathrm{~h} \mathrm{S.} \text {. aureus-challenged vs. } \\
\text { unchallenged control cells }\end{array}$ & $p$-value & \#Molecules \\
\hline RNA Post-Transcriptional Modification & $9.24 \mathrm{E}-15-1.62 \mathrm{E}-02$ & 42 \\
\hline Cell Cycle & $8.61 \mathrm{E}-10-1.62 \mathrm{E}-02$ & 95 \\
\hline Cellular Growth and Proliferation & $8.88 \mathrm{E}-10-1.37 \mathrm{E}-02$ & 202 \\
\hline Cell Death and Survival & $4.29 \mathrm{E}-08-1.62 \mathrm{E}-02$ & 187 \\
\hline Gene Expression & $3.25 \mathrm{E}-07-6.69 \mathrm{E}-03$ & 156 \\
\hline
\end{tabular}

in the late response of cells $(24 \mathrm{hpc})$ to both $E$. coli and $S$. aureus.

Similar late response effects in terms of most affected with molecular and cellular functions comprising "RNA post-transcriptional modification", "cell cycle", "cellular growth and proliferation" and "cell death and survival" were apparent in PMEC at $24 \mathrm{hpc}$ with $E$. coli and $S$. aureus, respectively, compared with unchallenged control cells. In contrast, differentially expressed genes associated with "cellular development" or "gene expression" were most affected by long-term challenge $(24 \mathrm{~h})$ with E. coli and S. aureus, respectively. Overall, PMEC are more responsive to the challenge with $E$. coli than $S$. aureus as early as $3 \mathrm{hpc}$ and as late as $24 \mathrm{hpc}$ in term of the number of differentially expressed genes involved in molecular and cellular functions (243 vs 41 at $3 \mathrm{hpc}$; 868 vs 682 at 24 hpc, see also Table 1).
Genes of different canonical pathways are involved in response of PMEC to pathogen challenge dependent on pathogen species and incubation time

At $3 \mathrm{hpc}$, IPA analysis identified 250 canonical pathways affected by the challenge with $E$. coli compared to 170 pathways by $S$. aureus. After long-term challenge (24 h) of PMEC with E. coli or S. aureus 295 and 267 canonical pathways were affected, respectively.

The most prominent genes which were significantly up-regulated in PMEC at $3 \mathrm{hpc}$ with $E$. coli encode proinflammatory cytokines and chemokines (chemokine (C-C motif) ligand 2, CCL2; chemokine (C-X-C motif) ligands CXCL1, CXCL2, CXCL3, and CXCL6; interleukin 1 alpha, IL1A), cell adhesion proteins (vascular cell adhesion molecule 1, VCAM1; intercellular adhesion molecule, ICAM1; integrin beta 3, ITGB3), and interferon signaling proteins (interferon-induced protein with tetratricopeptide repeats, IFIT1 and IFIT3; interferon receptors, IFNAR1 and IFNAR2) responsible for pathogen recognition by granulocytes and the first line of host defense against bacterial infection (Table 2).

Consistent with the up-regulation of the metabolism and degradation of various substrates (bupropion, acetone, nicotine, and melatonin) and estrogen biosynthesis in PMEC at $3 \mathrm{hpc}$ with $S$. aureus, the most represented up-regulated genes involved in these canonical pathways are cytochrome P450, family 1, subfamily A, polypeptide 1

Table 2 Up-regulated canonical pathways in PMEC at 3 hpc E. coli-challenged vs. unchallenged control cells

Canonical pathway (Genes involved in pathway) $\quad p$-value

Granulocyte Adhesion and Diapedesis

(CXCL3,IL1A,VCAM1,ICAM1,CCL2,CLDN1,CXCL1,CXCL2,IL1RAP, $8.52 \mathrm{E}-11$ CXCL6,ITGB3)

Interferon Signaling (IFIT3,IFIT1, JAK2,IFNAR2,IFNAR1,IRF1)

Agranulocyte Adhesion and Diapedesis (CXCL3,IL1A,VCAM1,ICAM1,CCL2,CLDN1,CXCL1,CXCL2,CXCL6)

4.92E-08

Hepatic Fibrosis/Hepatic Stellate Cell Activation (CXCL3,IL1A,VCAM1,ICAM1,CCL2,IFNAR2,IL1RAP,IFNAR1)

Role of IL-17A in arthritis

2.43E-06 (CXCL3,NFKBIA,CCL2,CXCL1,CXCL6)

S. aureus-challenged vs. unchallenged control cells

Canonical pathway (Genes involved in pathway)

p-value

Bupropion Degradation

3.44E-06

Acetone Degradation I (to Methylglyoxal)

3.86E-06

Estrogen Biosynthesis

$1.11 \mathrm{E}-05$

Nicotine Degradation III

2.87E-05

Melatonin Degradation I

3.39E-05

(CYP1A1,CYP3A4,CYP1B1 are involved in all five canonical pathways)

Top five categories of up-regulated canonical pathways in PMEC at $3 \mathrm{hpc}$ with $E$. coli and S. aureus, respectively, compared with unchallenged control cells with their respective $p$-value and genes involved in each pathway obtained from IPA software. 
(CYP1A1), CYP3A4 and CYP1B1 encoding monooxygenases (Table 2).

Furthermore, most of the significantly up-regulated canonical pathways, which were identified in PMEC at $3 \mathrm{hpc}$ with $E$. coli were also up-regulated at $24 \mathrm{hpc}$ with $E$. coli (Tables 2 and 3). For example, "interferon signalling" was also one of the top up-regulated canonical pathways in PMEC at $24 \mathrm{hpc}$ with S. aureus (Table 3).

In addition, at 24 hpc of PMEC with E. coli genes involved in inflammatory response signaling pathways such as "HMGB1 signaling" were significantly up-regulated, and at $24 \mathrm{hpc}$ with $S$. aureus genes regulating cell growth, proliferation, apoptosis and activation of natural killer cells were significantly up-regulated (Table 3 ).

Genes encoding growth factors (bone morphogenic protein 2, BMP2 and BMP4) as well as different transcription factors (FBJ murine osteosarcoma viral oncogene homolog, FOS; jun proto-oncogene, JUN; vav3 guanine nucleotide exchange factor, VAV3; early growth response 1, EGR1)

Table 3 Up-regulated canonical pathways in PMEC at 24 hpc

E. coli-challenged vs. unchallenged control cells

Canonical pathway (Genes involved in pathway)

p-value

Interferon Signaling

(IFIT3,IFIT1,PTPN2,MX1,TYK2,JAK2,STAT1,TAP1,IRF1)

Hepatic Fibrosis/Hepatic Stellate Cell Activation (CXCL3,VCAM1,IL1A,CTGF,CCL2,ICAM1,FGF2,IGFBP3,TGFA, IGF1R,FGFR2,STAT1,FAS,COL3A1)

Granulocyte Adhesion and Diapedesis (HRH1,CXCL3,VCAM1,IL1A,MMP7,ICAM1,SDC1,CLDN8, CCL2,CLDN1,CCL28,CXCL1,CXCL2,CXCL6,ITGB3)

Agranulocyte Adhesion and Diapedesis (CXCL3,HRH1,VCAM1,IL1A,MMP7,ICAM1,CLDN8,CCL2, CLDN1,CCL28,CXCL1,CXCL2,CXCL6)

HMGB1 Signaling

(MAP2K6,PIK3R3,FOS, IL 1A,VCAM1,ICAM1,

RHOQ, CCL2,DIRAS3,FNBP1, KAT6B)

S. aureus-challenged vs. unchallenged control cells

Canonical pathway (Genes involved in pathway)

Interferon Signaling

(IFIT3,IFIT1,PTPN2,TYK2,JAK2,BCL2)

$1.31 \mathrm{E}-06$

4.17E-06

Growth Hormone Signaling

(PIK3R3,FOS,SOCS6,IGF1R,IGFBP3,RPS6KA5,SOCS4,JAK2, PRKCZ,PRKD1)

Hepatic Fibrosis/Hepatic Stellate Cell Activation

(VCAM1,CTGF,IGF1R,IGFBP3,FGFR2,SERPINE1,COL3A1,BCL2)

Thrombopoietin Signaling

(PIK3R3,FOS,IRS2,JAK2,PRKCZ,PRKD1)

IGF-1 Signaling

(PIK3R3,FOS,YWHAG,CTGF,SOCS6,IGFIR,IGFBP3,IRS2,SOCS4, JAK2,PRKCZ)

Top five categories of up-regulated canonical pathways in PMEC at $24 \mathrm{hpc}$ with $E$. coli and S. aureus, respectively, compared with unchallenged control cells with their respective $p$-value and genes involved in each pathway obtained from IPA software. involved in BMP, IL-2 and TGF-beta signaling pathways are significantly down-regulated at $3 \mathrm{hpc}$ with $E$. coli (Table 4). "Differential regulation of cytokine production in macrophages and T helper cells by IL-17A and IL-17 F" and "MIF regulation of innate immunity" are some of the top five significantly down-regulated canonical pathways, critically involved in early response $(3 \mathrm{hpc})$ of PMEC to challenge with $S$. aureus and which are different from early response ( $3 \mathrm{hpc}$ ) of the cells to E. coli (Table 4). The most prominent down-regulated genes, which are involved in almost all of these pathways, encode transcription factor FOS and the cytokines colony stimulating factor 2 (CSF2) and CXCL1.

Canonical pathways regulating cell cycle and protein ubiquitination are some of the top five significantly down-regulated canonical pathways, which were mostly affected in PMEC at $24 \mathrm{hpc}$ with $E$. coli as well as at $24 \mathrm{hpc}$ with S. aureus (Table 5). Genes involved in these pathways encode heat shock proteins (DnaJ (Hsp40) homolog, subfamily C, member 9, DNAJC9; DNAJC11; DnaJ (Hsp40) homolog, subfamily A, member 1 ,

Table 4 Down-regulated canonical pathways in PMEC at 3 hpc

E. coli-challenged vs. unchallenged control cells

Canonical pathway (Genes involved in pathway) $\quad p$-value

BMP signaling pathway

(SOSTDC1, JUN,BMP4,BMP2)

1.27E-04

Regulation of IL-2 Expression in Activated and Anergic 1.55E-04

T Lymphocytes

(FOS,JUN,NFKBIA,VAV3)

TGF-b Signaling

(FOS,JUN,BMP4,BMP2)

1.79E-04

T Cell Receptor Signaling

2.84E-04

(FOS,JUN,NFKBIA,VAV3)

PKCq Signaling in T Lymphocytes

(FOS,JUN,NFKBIA,VAV3,MAP3K8)

\begin{tabular}{ll}
\hline S. aureus-challenged vs. unchallenged control cells & \\
\hline Canonical pathway (Genes involved in pathway) & $p$-value
\end{tabular}

Differential Regulation of Cytokine Production in $\quad 1.75 \mathrm{E}-04$

Macrophages and T Helper Cells by IL-17A and IL-17 F

(CXCL1,CSF2)

Role of Tissue Factor in Cancer (EGR1, CXCL1,JAK2,CSF2)

2.09E-03 Differential Regulation of Cytokine Production in Intestinal Epithelial Cells by IL-17A and IL-17 F (CXCL1,CSF2)

IL-17A Signaling in Gastric Cells (FOS,CXCL1) (FOS,PTGS2)

Top five categories of down-regulated canonical pathways in PMEC at $3 \mathrm{hpc}$ with $E$. coli and S. aureus, respectively, compared with unchallenged control cells with their respective $p$-value and genes involved in each pathway obtained from IPA software. 
Table 5 Down-regulated canonical pathways in PMEC at 24 hpc

E. coli-challenged vs. unchallenged control cells

Canonical pathway (Genes involved in pathway)

Estrogen-mediated S-phase Entry

(CCNA2,E2F4,CCNE1,TFDP1,E2F1,CDK2)

Protein Ubiquitination Pathway

(USP28,PSMB9,DNAJC9,MED20,HSPA1A/HSPA1B,HSPH1,

UBE2N, UBE2R2,HSPA6,CDC23,UBE2S,DNAJA1,HSPA5,TAP1, DNAJC11,USP31,USP3,PSMD12,USP46,USP34,BIRC)

Adenine and Adenosine Salvage I

(PNP)

Phosphatidylglycerol Biosynthesis II (Non-plastidic) (GPAM,ABHD5,PTPMT1,MBOAT2)

Cell Cycle: G1/S Checkpoint Regulation

(E2F4,CCNE1,CCND2,TFDP1,E2F1,GNL3,CDK2)

S. aureus-challenged vs. unchallenged control cells

Canonical pathway (Genes involved in pathway)

Phosphatidylglycerol Biosynthesis II (Non-plastidic) (GPAM,ABHD5,PTPMT1,MBOAT2)

Protein Ubiquitination Pathway

(DNAJC9,HSPA1A/HSPA1B,HSPH1,UBE2N,UBE2R2,HSPA6,

DNAJC25,CDC23,UBE2S,DNAJA1,HSPA5,DNAJC11,

PSMD12,USP46,USP34)

Aldosterone Signaling in Epithelial Cells

(ICMT,DNAJC9,HSPA1A/HSPATB,HSPH1,HSPA6,DNAJC25,

DNAJA1,HSPA5,PRKCZ,DNAJC11,PIK3R3,SCNN1G,PRKD1)

Estrogen-mediated S-phase Entry

(E2F4,CCNE1,TFDP1,E2F1)

Vitamin-C Transport

(SLC2A1,TXN,TXNRD1)

Top five categories of down-regulated canonical pathways in PMEC at $24 \mathrm{hpc}$ with E. coli and S. aureus, respectively, compared with unchallenged control cells with their respective $p$-value and genes involved in each pathway obtained from IPA software.

DNAJA1; heat shock $70 \mathrm{kDa}$ protein 1A/1B, HSPA1A/ HSPA1B; heat shock $70 \mathrm{kDa}$ protein 6, HSPA6; heat shock $105 \mathrm{kDa} / 110 \mathrm{kDa}$ protein 1 , HSPH1), cell cycle and cell growth regulating proteins (cell division cycle 23, CDC23; ubiquitin-conjugating enzyme E2S, UBE2S; ubiquitin-conjugating enzyme E2R2, UBE2R2) and ubiquitin specific peptidases (USP34, USP46) (Table 5).

"iNOS signalling" is one of the top five shared canonical pathways, which was affected at $3 \mathrm{hpc}$ with $E$. coli and $S$. aureus, respectively (data not shown), indicating the production of radical effectors of the innate immune system to eliminate invading pathogens. The top five shared canonical pathways, which were affected at $24 \mathrm{hpc}$ with the respective pathogens, include Janus kinase 2 (JAK2), insulin-like growth factor 1 (IGF-1) and signal transducer and activator of transcription 3 (STAT3) signaling indicating the activation of cytokinemediated immune response and regulatory effects on cell proliferation, apoptosis and migration (data not shown).
Different upstream regulators are involved in response of PMEC to the challenge with E. coli or S. aureus

Using IPA, we considered the top five upstream regulators when comparing pathogen challenged vs. unchallenged PMEC. We found considerable overlap in the identity and direction of activation of these upstream regulators between the compared data sets.

"IL1B" (interleukin-1 beta), "lipopolysaccharide", "IRAK4" (interleukin-1 receptor-associated kinase 4), "TNF" (tumor necrosis factor) and "cycloheximide" are the top five upstream regulators during the early response $(3 \mathrm{hpc})$ of cells to $E$. coli (Table 6). In contrast, at 3 hpc of cells with S. aureus, "beta-estradiol", "ESR1" (estrogen receptor 1), "U0126" (1,4-diamino-2,3-dicyano-1,4-bis[2-aminophenylthio] butadiene), "3-methylcholanthrene" and "paclitaxel" are the top five upstream regulators associated with host-pathogen interaction (Table 6). While upstream regulators of the early response ( $3 \mathrm{hpc}$ ) of PMEC to E. coli and S. aureus are completely different from another, at $24 \mathrm{hpc}$ with the respective pathogen species, "RAF1" (proto-oncogene serine/ threonine-protein kinase 1) and "PD98059" (2'-Amino-3'methoxyflavone) were involved in both host-pathogen interactions. Furthermore, "IKBKB" (inhibitor of kappa light polypeptide gene enhancer in B-cells, kinase beta), "TGFB1" (transforming growth factor beta 1), "HGF" (hepatocyte growth factor) and "E2F1" (E2F transcription factor 1), "TP53" (tumor protein p53), "INSR" (insulin receptor) were considered as the top upstream regulators in PMEC at $24 \mathrm{hpc}$ with E. coli and S. aureus, respectively (Table 6). The identified transcriptional upstream regulators affect the observed gene expression patterns after pathogen stimulation and control the complex cellular response mechanisms e.g. proliferation, apoptosis, migration and cell cycle progression to fine-tune the innate immune response of PMEC (Table 6).

\section{Different genes are involved in "inflammatory response" of PMEC challenged with E. coli or S. aureus}

With particular focus on differentially expressed genes annotated by IPA as signaling molecules involved in "inflammatory response", heatmaps were generated to illustrate the details of the defense mechanisms of PMEC to challenge with $E$. coli or $S$. aureus.

Our data show that more inflammatory response genes were up- and down-regulated at $24 \mathrm{~h}$ than at $3 \mathrm{~h}$ after pathogen challenge, and following challenge with $E$. coli than challenge with $S$. aureus (Figures $4 \mathrm{~A}$ and B). In the early inflammatory response $(3 \mathrm{hpc}$ ) of the cells to $E$. coli 40 genes were involved, mainly encoding cytokines, enzymes, transcription regulators and transmembrane receptors (Figure 4A). Most of these genes were upregulated (maximum FC 6.68) rather than downregulated (minimum FC -1.84 ). Only nine inflammatory response genes were affected at $3 \mathrm{hpc}$ of the cells with 
Table 6 Upstream regulators and their biological functions

$3 \mathrm{~h} \mathrm{E}$. coli-challenged vs. unchallenged $p$-value of

control cells overlap

IL1B (proinflammatory; proliferation; differentiation; $\quad 6.80 \mathrm{E}-23$

INSR (proliferation; growth; differentiation; migration; mitogenesis)

PD98059 (inhibitor of MAP kinase kinase; apoptosis; proliferation; migration)

Top five categories of upstream regulators and their functions in PMEC at 3 $\mathrm{hpc}$ and at $24 \mathrm{hpc}$ with E. coli and S. aureus, respectively, compared with unchallenged control cells with their respective $p$-value of overlap in each class obtained from IPA software.

S. aureus (Figure 4A). Equal amounts of these genes were up- and down-regulated (maximum FC 3.38; minimum FC -2.17) and most of them encode enzymes, cytokines and transcription regulators. Four out of the nine genes affected by challenge with $S$. aureus were also affected by challenge with $E$. coli.
In the late inflammatory response $(24 \mathrm{hpc})$ of the cells to $E$. coli 70 genes were involved, mainly encoding enzymes, cytokines, transmembrane receptors, transcription regulators and kinases (Figure $4 \mathrm{~B}$ ). Equal amounts of these genes were up- and down-regulated (maximum FC 7.87; minimum FC -2.51). In contrast, only 17 inflammatory response genes were affected at $24 \mathrm{hpc}$ of the cells with $S$. aureus, mainly encoding enzymes, kinases, transmembrane receptors, transcription regulators and G-protein coupled receptors (Figure 4B). Moreover, equal amounts of these genes were up- and down-regulated (maximum FC 2.38; minimum FC -4.28). Eleven of the 17 genes involved in late inflammatory response of the cells to $S$. aureus were also affected by challenge with $E$. coli.

\section{Gene network analysis revealed different key molecules} regulating defense mechanisms of PMEC against $E$. coli and S. aureus

Gene interactions were examined using IPA based on the known contributions of genes to regulatory networks in order to identify key regulators of the specific immune response of PMEC to pathogen challenge. The analysis was focused on the top 50 up-regulated and the top 50 downregulated genes at $3 \mathrm{hpc}$ and at $24 \mathrm{hpc}$ with $E$. coli and $S$. aureus. Figure 5 shows that the networks of key regulatory genes associated with host response to challenge with E. coli are more complex than that of challenge with $S$. aureus. Especially at $3 \mathrm{hpc}$ with $E$. coli a wider range of cytokines and growth factors were induced (Figure 5A) compared to $3 \mathrm{~h}$ challenge with $S$. aureus (Figure $5 \mathrm{~B}$ ). Our results indicated key regulatory functions of $I L 1 A, C X C L 2$, NFKBIA, mitogen-activated protein kinase kinase kinase 8 (MAP3K8), JUN, FOS and EGR1 within a network consisting of 32 response genes of PMEC at $3 \mathrm{hpc}$ with $E$. coli. In contrast, a network consisting of 14 response genes at 3 hpc with $S$. aureus was created with CSF2, prostaglandinendoperoxide synthase 2 (PTGS2), FOS and EGR1 as key regulators. Furthermore, CXCL1, CYP1B1, dual specificity phosphatase 6 (DUSP6), FOS and EGR1 were affected in PMEC at $3 \mathrm{hpc}$ with both pathogens.

Tumor necrosis factor (ligand) superfamily, member 10 (TNFSF10), NFKBIA, and FOS were found to be key regulators within a network consisting of 22 response genes at $24 \mathrm{hpc}$ of PMEC with E. coli (Figure 5C). In contrast, a network consisting of 17 response genes at $24 \mathrm{hpc}$ with $S$. aureus was created with CSF2, FOS and proliferating cell nuclear antigen (PCNA) as key regulators (Figure 5D). VCAM1, MAP2K6, CYP1B1, leucyl-tRNA synthetase (LARS), proteasome activator subunit 3 (PSME3), CDC6 and FOS were affected in PMEC at $24 \mathrm{hpc}$ with both pathogens. Almost all of the named key regulatory genes, which were involved in defense mechanisms of PMEC against E. coli and S. aureus are categorized by IPA as genes of "inflammatory response". 


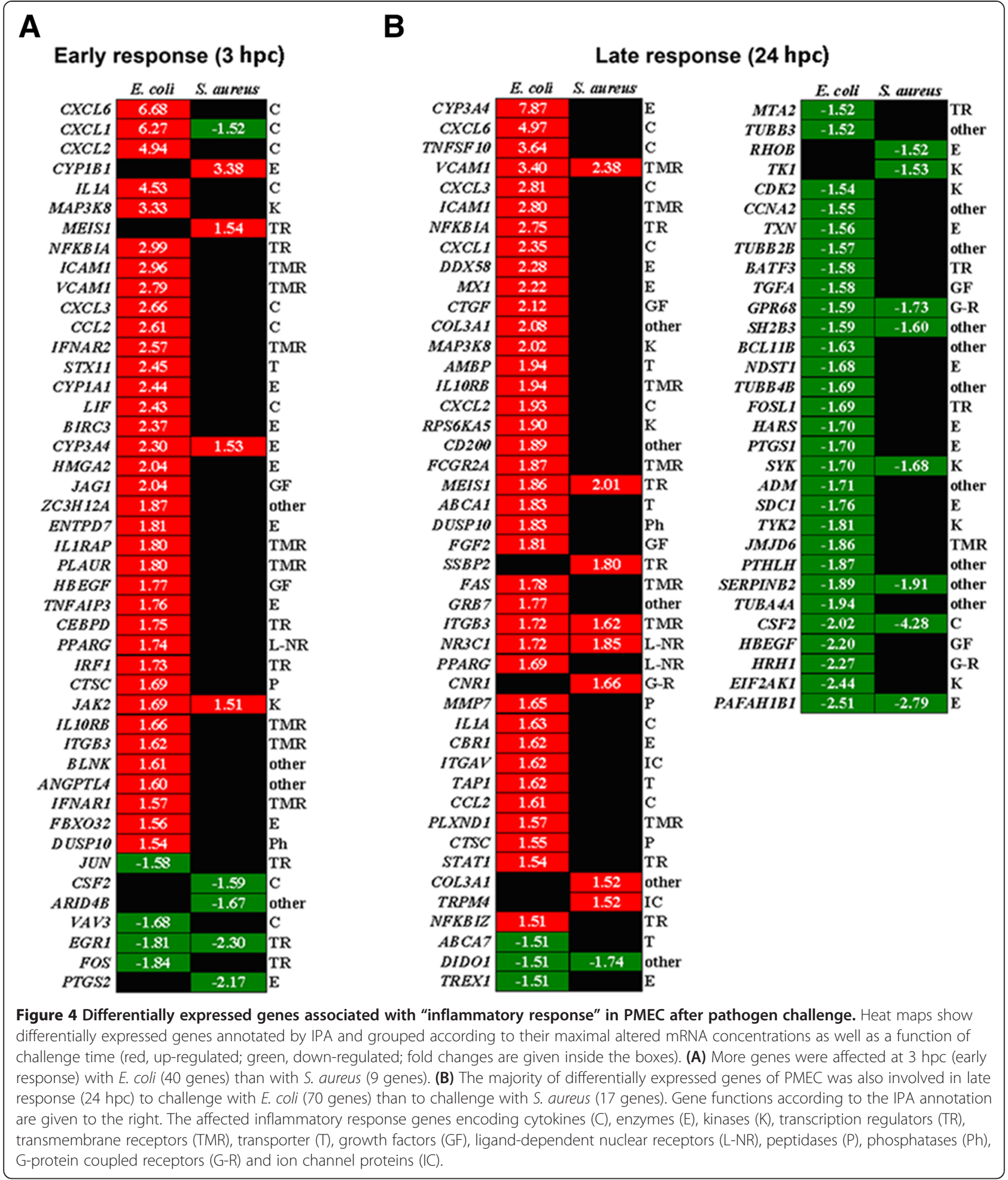

Validation of selected key transcripts by RT-qPCR In order to validate the microarray experiment, eight selected key transcripts encoding cytokines (IL1A, CXCL2, CCL2, TNFSF10, and CSF2), kinase (MAP3K8), transcription regulator (NFKBIA) and transmembrane receptor (VCAM1) associated with "inflammatory response" were analysed by RT-qPCR (Additional file 7). Between microarray and RT-qPCR data the correlation coefficients were highly significant and ranged between 0.84 and 0.98 for the selected genes. The RT-qPCR data 


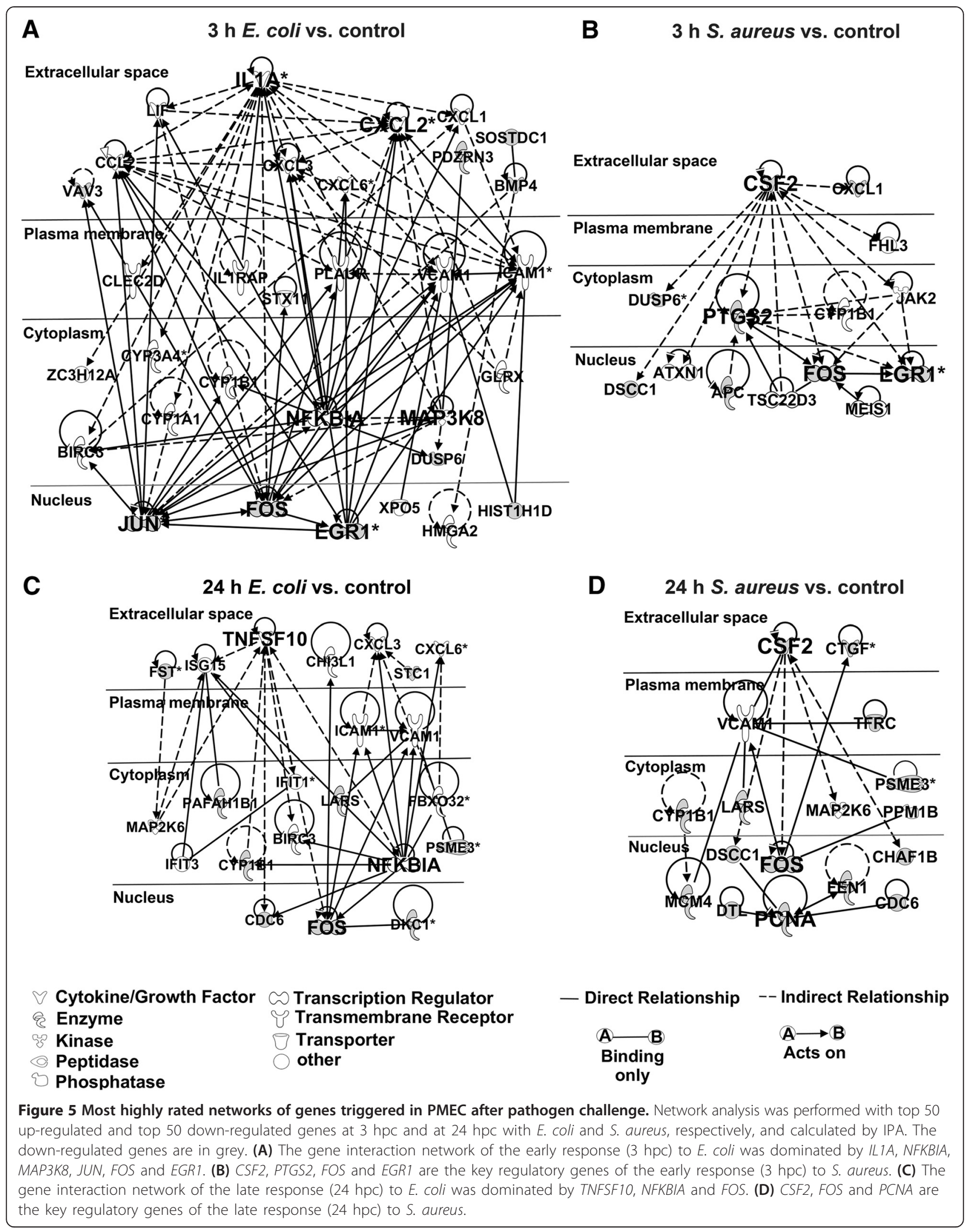


confirmed the selected results of microarray analysis with a good reproducibility.

\section{Discussion}

This study aimed to examine details about signaling pathways and key signaling molecules involved in PMEC defense mechanisms against pathogen infection which can help to elucidate the contribution of PMEC in pathogenesis of PDS in postpartum sows. To our knowledge, this is the first report describing the transcriptional response of PMEC at $3 \mathrm{hpc}$ and at $24 \mathrm{hpc}$ with heat-inactivated E. coli and S. aureus, in vitro.

However, it is difficult to compare the infection pressure of in vitro to in vivo situations. Therefore, we performed our experiments with heat-inactivated bacteria to provide standardized experimental conditions. In the PMEC model, the time course of the pathogen-specific immune response is well-defined and bacteria concentrations are constant throughout the entire experiments. This is to avoid bacterial overgrowth and depletion of nutrients during experiments. Since in vivo different cell types contribute to the immune response of the porcine mammary gland and the individual variation is high, PMEC model is less complex and therefore useful to describe molecular mechanisms of host-pathogen interactions with good reproducibility. We keep in mind that the PMEC model does not properly reflect the mastitis-induced regulation of chemokines and the complement system in the gland. Also the function of heat-labile proteins during inflammatory response may not be displayed in the PMEC model. Our study consists of a small number of biological replica, which might limit the statistical power, but the variability of pathogen-induced gene expression between biological cell culture replicates seems to be much less than that between pigs itself.

It is known that gram-negative (E. coli) and grampositive ( $S$. aureus) bacteria have relatively different structural and pathogenic profiles causing a similar, but time-delayed pattern of shock in the host [21]. The major pathogenic protein of gram-negative bacteria is the cell wall component LPS [22]. In contrast, gram-positive bacteria express cell wall-associated and secreted proteins (e.g., protein A, hemolysins, and phenol-soluble modulin) and cell wall components (e.g., peptidoglycan and alanylated lipoteichoic acid) which have been shown to be inflammatory [23]. While intramammary infection by $E$. coli is acute in nature and generally clears within a few days [24], infection by $S$. aureus is often less severe but results in a chronic infection that can persist for a life time of an animal [8]. The reasons for these pathogen-related differences in the host immune defense might reside in factors contributing to the innate immune system [25]. Innate recognition of pathogen-associated molecular patterns (PAMP) is mediated by evolutionary conserved pattern recognition receptors (PRR) [26]. For example, TLR2 recognizes cell wall components of gram-positive bacteria [27], whereas TLR4 recognizes LPS from gram-negative bacteria [28]. A simultaneous recognition of different pathogens is also possible, although the type of signal and co-receptor may differ. TLR2 mRNA expression was shown to be higher in porcine mammary glands after inoculation with $E$. coli as well as in sows that developed clinical signs of mastitis than in the non-inoculated mammary glands of sows that remained clinically healthy [9]. However, in our study, we did not observe significant changes in TLR expression of PMEC after both pathogen challenges.

\section{Main effects on molecular and cellular functions of PMEC after pathogen challenge depend on different initial host defense mechanisms}

The initial response of PMEC to the challenge with E. coli was more prominent than with $S$. aureus. During the long infection procedure $(24 \mathrm{hpc})$, a more intense host response with a maximum increase of shared upand down-regulated genes was identified after challenge with both pathogens. This is in accordance with observations by Günther et al. [8], who described that $S$. aureus elicits a much weaker and slower immune response in primary bovine mammary epithelial cells (pbMEC) than E. coli. To explain these, we focused on affected molecular and cellular functions in PMEC after pathogen challenge. While short-term as well as long-term challenge of PMEC with $E$. coli affected genes which are mostly involved in cellular processes such as growth, proliferation, development, death, survival, movement, and gene expression, short-term challenge with $S$. aureus rather induced metabolism of small molecules, lipids, vitamins and minerals. This is in line with the studies by Foster [29], who described that $S$. aureus cytotoxicity mainly depends on proteases, hyaluronidases, lipases, and nucleases which facilitate tissue destruction, membrane-damaging toxins that cause cytolytic effects in host cells, and superantigens which contribute to symptoms of septic shock. At 24 hpc of PMEC with the respective pathogens, the most affected molecular and cellular functions are more analog, for example the posttranscriptional modification of RNA, cell cycle, growth, proliferation, death, and survival. This is in agreement with other transcriptional profiling studies which have demonstrated that immune competent cells respond to bacterial stimuli with common transcriptional activation program which can be interpreted as generic "alarm signals" for infection [30,31]. Both, cell death and lipid metabolism were found to be among the most significant molecular functions altered in proteins of cows infected with either E. coli or S. aureus [32]. 


\section{Pathogen defense mechanisms of PMEC are driven by different canonical pathway mediators}

Our analysis of most affected canonical pathways and genes involved in that pathways in PMEC after pathogen challenge revealed that $E$. coli induced an early innate immune response at $3 \mathrm{hpc}$ indicated by a strong upregulation of genes encoding pro-inflammatory cytokines and chemokines such as CCL2, CXCL1, CXCL2, CXCL3, CXCL6, IL1A, and IL8 as well as cell adhesion proteins such as VCAM1, ICAM1, and ITGB3. The upregulation of cytokine production by epithelial cells is a key component of the host innate immune response [33]. Cronin et al. [34] reported that TLR4 on cells of the immune system of cow bind to LPS which in turn stimulates the secretion of the pro-inflammatory cytokines IL1B and IL6, and the chemokine IL8. The monokine IL1A was first appreciated as an endogenous pyrogen and lymphocyte-activating factor [35]. The NFkappaB-mediated secretion of the chemotactic factor IL8 and TLR-induced expression of vascular endothelial adhesion molecules promote the rapid recruitment and activation of immune cells including neutrophils, macrophages, lymphocytes and monocytes at the site of inflammation which kill invading bacteria [36-38]. These correlate well with our findings that the induced adhesion and activation of granulocytes, agranulocytes and stellate cells by PMEC at $3 \mathrm{hpc}$ and at $24 \mathrm{hpc}$ with E. coli were significant. In contrast, only stellate cell activation is one of the top five canonical pathways, which was affected at $24 \mathrm{hpc}$ of PMEC with S. aureus. Therefore, we suggest the early activation of cytokines and of cells of the innate immune system as critical factors driving the different downstream cascades of host defense mechanisms. Interferons play also an important role in the first line of defense of PMEC against E. coli indicated by the up-regulation of IFN signaling genes IFIT1 and IFIT3 as well as type I IFN receptor genes such as IFNAR1 and IFNAR2, which are expressed by leukocytes. An upregulation of this gene cluster was also present at $24 \mathrm{hpc}$ with $E$. coli as well as at $24 \mathrm{hpc}$ with $S$. aureus. The higher up-regulation of chemokines that target mononuclear leukocytes by LPS than by $S$. aureus culture supernatant is likely to be related to the differential activation of the type I IFN pathway, and could induce a different profile of the initial recruitment of leukocytes [13].

The enhanced gene expression of $I L-17 A$ in PMEC at $3 \mathrm{hpc}$ with $E$. coli is a sign for antibacterial activity of the cells as well, mediated by indirect enhancement of neutrophil migration and secretion of cytokines and chemokines to infected tissue. With regard to the innate immune response to infection, $I L-17 A$ was found in milk cell RNA extracts in the early phase $(8 \mathrm{hpc})$ of the inflammatory response [39] as well as in milk leukocytes from cows suffering from $S$. aureus mastitis [40,41]. In contrast, IL-17A signaling pathways were downregulated in PMEC at $3 \mathrm{hpc}$ with S. aureus. Genini et al. [31] stated that the comparison of E. coli and S. aureus infections in cattle in vivo reveals affected genes showing opposite regulation with the same altered biological functions and this provides evidence that $E$. coli can cause a stronger host response. Gilbert et al. [13] suggested that $E$. coli induces a more intense response associated with strong NF-kappaB stimulation and the recruitment of a wider repertoire of immune cells, whereas S. aureus interferes with cell DNA integrity and may induce a more restricted immune response involving the IL-17A pathway. In contrast to the short-term challenge of PMEC with $E$. coli, at $3 \mathrm{hpc}$ with $S$. aureus we observed a strong up-regulation of CYP1A1, CYP3A4 and $C Y P 1 B 1$ encoding monooxygenases, which have pivotal roles in primary and secondary metabolic pathways and are involved in the detoxification and elimination of reactive oxygen species and other poisonous compounds $[42,43]$. Thus, as expected canonical pathways including different metabolic degradation processes as well as estrogen biosynthesis were mostly affected in PMEC at $3 \mathrm{hpc}$ with $S$. aureus. Genes encoding the cell adhesion molecules VCAM1 and ITGB3 were also up-regulated in PMEC at $3 \mathrm{hpc}$ and at $24 \mathrm{hpc}$ with S. aureus. This can lead to an induction of infiltration of immune cells to the site of infection to act there as key factors in the host defense against invading pathogens [44]. These differences in the initial innate immune response of PMEC to E. coli or S. aureus are consistent with studies in mammary epithelial cells from cows and sheep where it was argued that the response of mammary epithelial cells (MEC) to $S$. aureus was not the result of an overwhelming cytotoxicity, because the early response was an increase of the reduction activity $[8,45]$. This may also explain a very rapid increase in somatic cell count (SCC) in bovine milk during $E$. coli infection compared to a slower but longer increase in S. aureus infections [46]. In general, most of the canonical pathways such as interferon signaling and the activation of immune competent cells, which were up-regulated in PMEC at $3 \mathrm{hpc}$ with E. coli were also up-regulated at $24 \mathrm{hpc}$ with $E$. coli and, to a lesser extent, at $24 \mathrm{hpc}$ with $S$. aureus. Additionally, at the same challenge time High-MobilityGroup-Protein B1 (HMGB1) signaling is induced by E. coli suggesting an activation of antigen-presenting dendritic cells [47]. Insulin-like growth factor 1 (IGF-1) signaling was induced in PMEC at $24 \mathrm{hpc}$ with S. aureus indicating an induction of SCC. It was reported that the concentration of IGF-1 and the numbers of SCC in milk of cows were greatly elevated in secretions of quarters affected by acute clinical as well as subclinical mastitis compared with the corresponding clinically healthy quarters [48]. The 
pathogen E. coli can also induce apoptosis in vivo and thereby properly contribute to a decrease of milk production in mastitis [49]. In our probe sets the expressions of both, pro- and anti-apoptotic genes, were modulated in PMEC, especially at $24 \mathrm{hpc}$ with both pathogens.

\section{Fine-tuning of host defense mechanisms is important for preventing host cell damage}

While a robust and rapid initiation of the host defense mechanism is essential for a successful pathogen clearance during the acute phase, on the other hand an excessive but ineffective immune defense can produce temporary or permanent damage of the host. Therefore, a restriction of an exuberant innate immune response is necessary to limit host defense. We observed an increased expression of genes encoding immune dampening factors such as NF-kappaB pathway suppressors IkappaB-alpha (NFKBIA) which function in the cytoplasm to sequester NF-kappaB, and the kinase MAP3K8 $[30,50]$ at $3 \mathrm{hpc}$ and at $24 \mathrm{hpc}$ of PMEC with E. coli, but not with $S$. aureus. Both, NF-kappaB and MAPK cascades are induced by myeloid differentiation primary response 88 (MyD88) which is activated by LPS [51]. In agreement with our results, an increased expression of NFKBIA was also reported at $4 \mathrm{~h}$ after infusion of LPS into mouse mammary glands [52]. The panel of immune suppressors in PMEC was extended by increased expression of TNFAIP8 at $24 \mathrm{hpc}$ with $E$. coli which functions in a negative feedback loop regulating TLR-ligand and TNF-induced responses [53]. Besides, the up-regulation of anti-inflammatory genes as well as the downregulation of pro-inflammatory genes balances the host immune response. For example, at $3 \mathrm{hpc}$ with $S$. aureus, we observed a down-regulation of CXCL1 and the cytokine CSF2 (also known as GM-CSF) in PMEC, which is contrary to challenge with $E$. coli. Proteins encoded by both genes are known to control the production, differentiation and recruitment of neutrophils and macrophages [54,55]. Neutrophils from cows affected by subclinical mastitis demonstrated a significant delay of apoptosis as compared with neutrophils obtained from healthy cows and were unresponsive to GM-CSF [56]. Gilbert et al. [13] observed an induction of CXCL1 and CSF2 at $3 \mathrm{hpc}$ and at $6 \mathrm{hpc}$ of bovine mammary epithelial cells (bMEC) with E. coli crude LPS, but not with $S$. aureus culture supernatant. Down-regulation of these genes could be a result of steroid hormones (e.g. glucocorticoid), which orchestrate physiological processes such as metabolism, immunity and development and suppress cytokines, adhesion molecules and inflammatory response proteins as well as the recruitment of leukocytes to allow a systemic response to external stresses and resources [57]. This is in congruence with our transcriptome analysis of PMEC highlighting steroid hormone (estrogen) biosynthesis as one of the most enriched canonical pathways at $3 \mathrm{hpc}$ with $\mathrm{S}$. aureus.

\section{Networks of specific pathogen-affected upstream and downstream regulators associated with inflammatory response emphasize the complexity of the innate immune response of PMEC}

The activation of downstream signal transduction pathways via phosphorylation, ubiquitination, or proteinprotein interactions, ultimately culminate in activation of transcription factors regulating the expression of genes involved in inflammation and antimicrobial host defenses [58]. Our results are in agreement with that, showing a down-regulation of genes encoding heatshock proteins which are involved in protein ubiquitination pathways in PMEC at $24 \mathrm{hpc}$ with E. coli as well as with $S$. aureus, and contributing to a decreasing receptor-mediated activation of the innate immune response.

Nevertheless, the common transcriptional response of PMEC to both pathogens is characterized by expression changes of genes interacting in activation, regulation and limitation of the innate immune response. Upstream analysis of genes mostly affected in PMEC at $3 \mathrm{hpc}$ with E. coli are associated with TLR4-mediated recognition of LPS and downstream signaling cascades involving $I L 1 B$, interleukin-1 receptor-associated kinase 4 (IRAK4) and $T N F$ to initiate local and systemic inflammatory response. This is in accordance with the study of Günther et al. [8], who reported that genes that are exclusively and most strongly up-regulated by $E$. coli may be clustered into a regulatory network with TNF-alpha and IL1. An association between clinical mastitis and local production of IL1-beta, IL6 and TNF-alpha is suggested in mammary glands of sows [26]. IL1-beta is found in greater concentration in milk of E. coli mastitis than in milk of $S$. aureus mastitis, and TNF-alpha is found in bovine milk in case of E. coli but not $S$. aureus mastitis $[40,59]$. In contrast, upstream regulation of the innate immune response of PMEC at $3 \mathrm{hpc}$ with $S$. aureus is mediated for example by beta-estradiol, known to regulate the innate immunity by suppressing the secretion and/or expression of pro-inflammatory mediators by human uterine epithelial cells, but also stimulates the production of antimicrobials [60]. Different upstream regulators affected in PMEC at $24 \mathrm{hpc}$ with $E$. coli and with $S$. aureus have similar functions by controlling gene expressions involved in the cell division cycle, apoptosis, cell differentiation, cell adhesion, cell migration and metabolism. This reflects the complexity of the innate immune response of PMEC to the respective pathogens. The networks of key regulatory genes associated with host response of PMEC challenged with $E$. coli are more complex than that challenged with S. aureus. Almost all 
of the key regulatory genes involved in the defense mechanisms against $E$. coli and S. aureus are categorized by IPA as genes of "inflammatory response". IL1A, CXCL2, TNFSF10, NFKBIA and MAP3K8 are the main key regulatory genes of the innate immune response of PMEC challenged with $E$. coli, which act on gene expression of JUN, FOS and EGR1, while challenge with S. aureus mostly affected gene expression of FOS, EGR1 and PCNA via CSF2 and PTGS2 signaling. Apart from the different mostly affected genes encoding proteins which act in several cell-to-cell communications or cytoplasmic protein interactions, their effects on regulation of transcription centered to the active down-regulation of some immediate early genes (EGR1, JUN, FOS) executing distinct biological functions.

Our results show that PMEC do not only pose a physical barrier against extracellular pathogens, but are immune competent as well. They are capable of recognizing invading pathogens and initiate local and systemic immune responses. The extent and the course of the infection depend on: (i) pathogen stimuli; (ii) pathogen recognition and (iii) immune status of the animal. Individual differences in one of these objects critically influence the innate host immune response and PDS pathogenesis. The much faster and stronger inflammatory response of PMEC to challenge with $E$. coli results from immediately induced IL1B and TNF signaling initiating the rapid mobilization of immune cells mediated by various cytokines and chemokines. In contrast, such strong and rapid effects on expressions of immune relevant genes are not elicited by challenge with $S$. aureus, which rather affected metabolic pathway signaling resulting in a more moderate innate immune response.

Overall, our results suggest PMEC as a suitable mechanistic model, which especially contributes the understanding of pathogenesis of porcine mastitis induced by $E$. coli or S. aureus, and generally confirm comprehensive expression patterns of innate immune response in other cell types as well as animal species. Further comparative investigations on these gene expression patterns of the innate immune response of PDS-negative and PDS-positive sows may aid elucidation of the PDS etiology.

\section{Additional files}

Additional file 1: Overview of differentially expressed genes at $3 \mathrm{~h}$ post-challenge with $E$. coli compared to unchallenged control. Table giving Affymetrix probe set numbers, fold changes (control vs. treatment), $p$-values and corresponding $q$-values, gene symbols and gene names.

Additional file 2: Overview of differentially expressed genes at $3 \mathrm{~h}$ post-challenge with $S$. aureus compared to unchallenged control. Table giving Affymetrix probe set numbers, fold changes (control vs. treatment), $p$-values and corresponding $q$-values, gene symbols and gene names.
Additional file 3: Overview of differentially expressed genes at $24 \mathrm{~h}$ post-challenge with $E$. coli compared to unchallenged control. Table giving Affymetrix probe set numbers, fold changes (control vs. treatment), $p$-values and corresponding q-values, gene symbols and gene names.

Additional file 4: Overview of differentially expressed genes at $24 \mathrm{~h}$ post-challenge with $S$. aureus compared to unchallenged control.

Table giving Affymetrix probe set numbers, fold changes (control vs. treatment), $p$-values and corresponding $q$-values, gene symbols and gene names.

Additional file 5: Sequences of oligonucleotide primers used for real-time PCR quantification. Table providing primer sequences, length of PCR products, annealing temperatures and GenBank accession number of respective nucleotide sequences.

Additional file 6: Principle component analysis. The 2D condition scatter plot view clustering of gene expressions in PMEC after challenge with E. coli (red dots) or S. aureus (blue dots) for $3 \mathrm{~h}$ and $24 \mathrm{~h}$ compared to unchallenged control (green dots). The two main principal components of the expression of the most significant genes show significant separation of the three biological replicates by location (PC1 and PC2). It is also shown that gene expression diverges most significantly with increasing treatment time. In contrast, the technical replicates show more consistent gene expression clusters. No outliers were detected.

Additional file 7: Comparison of microarray and RT-qPCR results for selected transcripts associated with "inflammatory response". Table giving fold changes, $p$-values and corresponding q-values detailed for various comparisons obtained with microarrays and RT-qPCR and correlation coefficient for the two methods.

\section{Competing interests}

The authors declare that they have no competing interests.

\section{Authors' contributions}

KW and NK designed the study. AJ and KW sampled the tissue probes during the slaughter process. DB and NK collected and classified the bacteria samples. AJ, DB, JG and KW designed and carried out the cell culture experiments and microscopy. EM coordinated the RNA sampling and RT-qPCR analyses. SP participated in the microarray analyses. MO performed the statistical and bioinformatic analyses of microarray data and RT-qPCR data. $\mathrm{AJ}$ and JG analysed and interpreted the data. AJ drafted the manuscript and prepared figures and tables. MO, EM, KW and NK critically revised the manuscript. All authors read and approved the final manuscript.

\section{Acknowledgements}

The authors are grateful for the excellent technical support from Angelika Deike, Hannelore Tychsen and Anette Jugert. This research project was funded by the German Federal Ministry of Education and Research (BMBF) in the research program "FUGATO - Functional Genome Analysis in Animal Organisms", project "geMMA - structural and functional analysis of the genetic variation of the MMA syndrome" (FKZ0315138).

\section{Author details}

IInstitute for Genome Biology, Leibniz-Institute for Farm Animal Biology, Wilhelm-Stahl-Allee 2, D-18196 Dummerstorf, Germany. ${ }^{2}$ Institute of Agricultural and Nutritional Sciences, Martin-Luther-University Halle-Wittenberg, Theodor-Lieser-Straße 11, D-06120 Halle (Saale), Germany. ${ }^{3}$ Institute for Animal Hygiene, Animal Welfare and Livestock Ethology, University of Veterinary Medicine Hannover, Foundation, Bischofsholer Damm 15, D-30173 Hannover, Germany.

Received: 23 September 2014 Accepted: 1 April 2015

Published online: 06 May 2015

\section{References}

1. Gerjets I, Kemper N (2009) Coliform mastitis in sows: a review. J Swine Health Prod 17:97-105

2. López J, Ubiergo A (2005) Pig Progress. Reed Business Information, Doetinchem, Netherlands 21:12-14 
3. Kemper N, Bardehle D, Lehmann J, Gerjets I, Looft H, Preissler R (2013) The role of bacterial pathogens in coliform mastitis in sows. Berl Munch Tierarztl Wochenschr 126:130-136

4. Gerjets I, Traulsen I, Reiners K, Kemper N (2011) Comparison of virulence gene profiles of Escherichia coli isolates from sows with coliform mastitis and healthy sows. Vet Microbiol 152:361-367

5. Preissler R, Hinrichs D, Reiners K, Looft H, Kemper N (2012) Estimation of variance components for postpartum dysgalactia syndrome in sows. J Anim Breed Genet 129:98-102

6. Bertschinger HU, Bühlmann A (2001) Absence of protective immunity in mammary glands after experimentally induced coliform mastitis. In: Congress, Swiss Association of Swine Medicine (ed) International Pig Veterinary Society. Proceedings of the 11th International Pig Veterinary Society Congress: 1-5 July 2001, Lausanne, Switzerland, p 175

7. Elmore RG, Martin CE, Berg P (1978) Absorption of Escherichia coli endotoxin from the mammmary glands and uteri of early postpartum sows and gilts. Theriogenol 10:439-445

8. Günther J, Esch K, Poschadel N, Petzl W, Zerbe H, Mitterhuemer S, Blum H, Seyfert HM (2011) Comparative kinetics of Escherichia coli- and Staphylococcus aureus-specific activation of key immune pathways in mammary epithelial cells demonstrates that $\mathrm{S}$. aureus elicits a delayed response dominated by interleukin6 (IL-6) but not by IL-1A or tumor necrosis factor alpha. Infect Immun 79:695-707

9. Zhu Y (2007) Early inflammatory response in periparturient sows to experimentally induced Escherichia coli mastitis. PhD thesis. Swedish University of Agricultural Sciences, Division of Reproduction, Department of Clinical Sciences, Faculty of Veterinary Medicine and Animal Science, Uppsala, Sweden

10. Zhu Y, Berg M, Fossum C, Magnusson U (2007) Proinflammatory cytokine mRNA expression in mammary tissue of sows following intramammary inoculation with Escherichia coli. Vet Immunol Immunopathol 116:98-103

11. Zhu Y, Fossum C, Berg M, Magnusson U (2007) Morphometric analysis of proinflammatory cytokines in mammary glands of sows suggests an association between clinical mastitis and local production of IL-1beta, IL-6 and TNF-alpha. Vet Res 38:871-882

12. Magnusson U, Pedersen Mörner A, Persson A, Karlstam E, Sternberg S, Kindahl H (2001) Sows intramammarily inoculated with Escherichia coli influence of time of infection, hormone concentrations and leucocyte numbers on development of disease. J Vet Med B Infect Dis Vet Public Health 48:501-512

13. Gilbert FB, Cunha $P$, Jensen $K$, Glass EJ, Foucras G, Robert-Granié C, Rupp R, Rainard P (2013) Differential response of bovine mammary epithelial cells to Staphylococcus aureus or Escherichia coli agonists of the innate immune system. Vet Res 44:40

14. Edgar R, Domrachev M, Lash A (2002) Gene expression omnibus: Ncbi gene expression and hybridization array data repository. Nucleic Acids Res 30:207-210

15. The National Center for Biotechnology Information Gene Expression Omnibus. www.ncbi.nlm.nih.gov/geo Accessed 16 December 2014

16. Kauffmann A, Gentleman R, Huber W (2009) arrayQualityMetrics-a bioconductor package for quality assessment of microarray data. Bioinformatics 25:415-416

17. Bourgon R, Gentleman R, Huber W (2010) Independent filtering increases detection power for high-throughput experiments. Proc Natl Acad Sci U S A 107:9546-9551

18. Storey JD, Tibshirani R (2003) Statistical significance for genomewide studies. Proc Natl Acad Sci U S A 100:9440-9445

19. Naraballobh W, Chomdej S, Muráni E, Wimmers K, Ponsuksili S (2010) Annotation and in silico localization of the Affymetrix GeneChip Porcine Genome Array. Arch Anim Breed 53:230-238

20. Vandesompele J, De Preter K, Pattyn F, Poppe B, Van Roy N, De Paepe A, Speleman F (2002) Accurate normalization of real-time quantitative RT-PCR data by geometric averaging of multiple internal control genes. Genome Biol 3:RESEARCH0034

21. Sriskandan S, Cohen J (1999) Gram-positive sepsis. Mechanisms and differences from gram-negative sepsis. Infect Dis Clin North Am 13:397-412

22. Wellnitz O, Reith P, Haas SC, Meyer HHD (2006) Immune relevant gene expression of mammary epithelial cells and their influence on leukocyte chemotaxis in response to different mastitis pathogens. Vet Med 51:125-132

23. Fournier B, Philpott DJ (2005) Recognition of Staphylococcus aureus by the innate immune system. Clin Microbiol Rev 18:521-540
24. Smith KL, Hogan JS (1993) Environmental mastitis. Vet Clin N Am Food Anim Pract 9:489-498

25. Miller SI, Ernst RK, Bader MW (2005) LPS, TLR4 and infectious disease diversity. Nat Rev Microbiol 3:36-46

26. Aderem A, Ulevitch RJ (2000) Toll-like receptors in the induction of the innate immune response. Nature 406:782-787

27. Yoshimura A, Lien E, Ingalls RR, Tuomanen E, Dziarski R, Golenbock D (1999) Cutting edge: recognition of Gram-positive bacterial cell wall components by the innate immune system occurs via Toll-like receptor 2. J Immunol 163:1-5

28. Hirschfeld M, Ma Y, Weis JH, Vogel SN, Weis JJ (2000) Cutting edge: repurification of lipopolysaccharide eliminates signaling through both human and murine toll-like receptor 2. J Immunol 165:618-622

29. Foster TJ (2005) Immune evasion by Staphylococci. Nat Rev Microbiol 3:948-958

30. Jenner RG, Young RA (2005) Insights into host responses against pathogens from transcriptional profiling. Nat Rev Microbiol 3:281-294

31. Genini S, Badaoui B, Sclep G, Bishop SC, Waddington D, Pinard van der Laan MH, Klopp C, Cabau C, Seyfert HM, Petzl W, Jensen K, Glass EJ, de Greeff A, Smith HE, Smits MA, Olsaker I, Boman GM, Pisoni G, Moroni P, Castiglioni B, Cremonesi P, Del Corvo M, Foulon E, Foucras G, Rupp R, Giuffra $E$ (2011) Strengthening insights into host responses to mastitis infection in ruminants by combining heterogeneous microarray data sources. BMC Genomics 12:225

32. Ibeagha-Awemu EM, Ibeagha AE, Messier S, Zhao X (2010) Proteomics, genomics, and pathway analyses of Escherichia coli and Staphylococcus aureus infected milk whey reveal molecular pathways and networks involved in mastitis. J Proteome Res 9:4604-4619

33. Kolls JK, McCray PB, Jr, Chan YR (2008) Cytokine-mediated regulation of antimicrobial proteins. Nat Rev Immunol 8:829-835

34. Cronin JG, Turner ML, Goetze L, Bryant CE, Sheldon IM (2012) Toll-like receptor 4 and MYD88-dependent signaling mechanisms of the innate immune system are essential for the response to lipopolysaccharide by epithelial and stromal cells of the bovine endometrium. Biol Reprod 86:51

35. Dinarello CA (1991) Interleukin-1 and interleukin-1 antagonism. Blood 77:1627-1652

36. Harada A, Sekido N, Akahoshi T, Wada T, Mukaida N, Matsushima K (1994) Essential involvement of interleukin-8 (IL-8) in acute inflammation. J Leukoc Biol 56:559-564

37. Paape MJ, Shafer-Weaver K, Capuco AV, Van Oostveldt K, Burvenich C (2000) Immune surveillance of mammary tissue by phagocytic cells. Adv Exp Med Biol 480:259-277

38. Leitner G, Eligulashvily R, Krifucks O, Perl S, Saran A (2003) Immune cell differentiation in mammary gland tissues and milk of cows chronically infected with Staphylococcus aureus. J Vet Med B Infect Dis Vet Public Health 50:45-52

39. Rainard P, Cunha P, Bougarn S, Fromageau A, Rossignol C, Gilbert FB, Berthon P (2013) T helper 17-associated cytokines are produced during antigen-specific inflammation in the mammary gland. PLoS One 8:e63471

40. Riollet C, Mutuel D, Duonor-Cerutti M, Rainard P (2006) Determination and characterization of bovine interleukin-17 cDNA. J Interferon Cytokine Res 44:141-149

41. Tao W, Mallard B (2007) Differentially expressed genes associated with Staphylococcus aureus mastitis of Canadian Holstein cows. Vet Immunol Immunopathol 44:201-211

42. Barouki R, Morel Y (2001) Repression of cytochrome P450 1A1 gene expression by oxidative stress: mechanisms and biological implications. Biochem Pharmacol 61:511-516

43. Murray Gl, Melvin WT, Greenlee WF, Burke MD (2001) Regulation, function, and tissue-specific expression of cytochrome P450 CYP1B1. Annu Rev Pharmacol Toxicol 41:297-316

44. Paape M, Mehrzad J, Zhao X, Detilleux J, Burvenich C (2002) Defense of the bovine mammary gland by polymorphonuclear neutrophil leukocytes. J Mammary Gland Biol Neoplasia 7:109-121

45. Bonnefont CM, Rainard P, Cunha P, Gilbert FB, Toufeer M, Aurel MR, Rupp R, Foucras G (2012) Genetic susceptibility to $S$. aureus mastitis in sheep: differential expression of mammary epithelial cells in response to live bacteria or supernatant. Physiol Genomics 44:403-416

46. De Haas Y, Veerkamp RF, Barkema HW, Gröhn YT, Schukken YH (2004) Associations between pathogen-specific cases of clinical mastitis and somatic cell count patterns. J Dairy Sci 87:95-105 
47. Dumitriu IE, Baruah P, Bianchi ME, Manfredi AA, Rovere-Querini P (2005) Requirement of HMGB1 and RAGE for the maturation of human plasmacytoid dendritic cells. Eur J Immunol 35:2184-2190

48. Liebe A, Schams D (1998) Growth factors in milk: interrelationships with somatic cell count. J Dairy Res 65:93-100

49. Long E, Capuco AV, Wood DL, Sonstegard T, Tomita G, Paape MJ, Zhao X (2001) Escherichia coli induces apoptosis and proliferation of mammary cells. Cell Death Differ 8:808-816

50. Bottero V, Imbert V, Frelin C, Formento JL, Peyron JF (2003) Monitoring NF-kappa B transactivation potential via real-time PCR quantification of I kappa B-alpha gene expression. Mol Diagn 44:187-194

51. Fujihara M, Muroi M, Tanamoto K, Suzuki T, Azuma H, Ikeda H (2003) Molecular mechanisms of macrophage activation and deactivation by lipopolysaccharide: roles of the receptor complex. Pharmacol Ther 100:171-194

52. Zheng J, Watson AD, Kerr DE (2006) Genome-wide expression analysis of lipopolysaccharide-induced mastitis in a mouse model. Infect Immun 44:1907-1915

53. Dixit VM, Green S, Sarma V, Holzman LB, Wolf FW, O'Rourke K, Ward PA Prochownik EV, Marks RM (1990) Tumor necrosis factor-alpha induction of novel gene products in human endothelial cells including a macrophagespecific chemotaxin. J Biol Chem 265:2973-2978

54. Mantovani A, Cassatella MA, Costantini C, Jaillon S (2011) Neutrophils in the activation and regulation of innate and adaptive immunity. Nat Rev Immunol 11:519-53

55. De Filippo K, Dudeck A, Hasenberg M, Nye E, van Rooijen N, Hartmann K, Gunzer M, Roers A, Hogg N (2013) Mast cell and macrophage chemokines CXCL1/CXCL2 control the early stage of neutrophil recruitment during tissue inflammation. Blood 121:4930-4937

56. Boutet $P$, Boulanger $D$, Gillet $L$, Vanderplasschen A, Closset $R$, Bureau $F$, Lekeux P (2004) Delayed neutrophil apoptosis in bovine subclinical mastitis. J Dairy Sci 87:4104-4114

57. Regan JC, Brandão $A S$, Leitão $A B$, Mantas Dias $A R$, Sucena $E$, Jacinto $A$, Zaidman-Rémy A (2013) Steroid hormone signaling is essential to regulate innate immune cells and fight bacterial infection in Drosophila. PLoS Pathog 9:e1003720

58. Akira S, Uematsu S, Takeuchi O (2006) Pathogen recognition and innate immunity. Cell 124:783-801

59. Bannerman DD, Paape MJ, Lee JW, Zhao X, Hope JC, Rainard P (2004) Escherichia coli and Staphylococcus aureus elicit differential innate immune responses following intramammary infection. Clin Diagn Lab Immunol 11:463-472

60. Fahey JV, Wright JA, Shen L, Smith JM, Ghosh M, Rossoll RM, Wira CR (2008) Estradiol selectively regulates innate immune function by polarized human uterine epithelial cells in culture. Mucosal Immunol 1:317-325

\section{Submit your next manuscript to BioMed Central and take full advantage of:}

- Convenient online submission

- Thorough peer review

- No space constraints or color figure charges

- Immediate publication on acceptance

- Inclusion in PubMed, CAS, Scopus and Google Scholar

- Research which is freely available for redistribution 